\title{
The colliding worlds of art and science
}

\author{
Contrary to common belief, art, science and technology have always played off one another.
}

\author{
Arthur I. Miller
}

"A ny distinction between art and science is becoming increasingly irrelevant," says Aaron Koblin, a pioneer in data visualization art and formerly creative director of the data arts team at Google. The artists in this issue exemplify this assessment.

When thinking of people who, in retrospect, were artists as well as scientists and so demonstrate that there has always been an interplay between art and science, two names immediately leap to mind: Leonardo da Vinci and Galileo. Leonardo's anatomical sketches are artistic masterpieces but also scientific explorations of the human form. Galileo studied art in order to depict accurately what he saw through his telescope. This symbiosis between art and science was temporarily interrupted by the publication of Isaac Newton's Principia in 1687, which set the foundations of a new physics. Many by the time of Enlightenment considered science to be the key to glimpsing physical reality, and art to be merely frivolous. Starting from about the mid-nineteenth century, however, the two realms started to merge again.

The twentieth century began with dramatic signs of rapprochement. Einstein, thinking like an artist, struggled to have the equations of physics reflect the beauty and symmetries he saw in nature. In this way, he discovered relativity theory, and symmetry became a guide for physics research. Picasso, thinking like a scientist, turned to developments in mathematics, science and technology to create cubism, aiming to reduce nature to geometrical forms that could be viewed from every perspective at once. Their creative struggles suggest that at the nascent moment of discovery, distinctions blur between art and science.

During the first half of the twentieth century, artists used the ideas of science but not the materials. This changed in the second half of the century when a plethora of electronics became available in addition to developments in computers.

A memorable product of this era was the 1966 event 9 Evenings: Theatre and Engineering, the first ever large-scale collaboration between artists, engineers and scientists. Everyone involved agreed that they were seeing a brandnew art movement. This was the brainchild of Billy Klüver, an engineer at that hotbed of ideas, Bell Labs in Murray Hill, New Jersey,

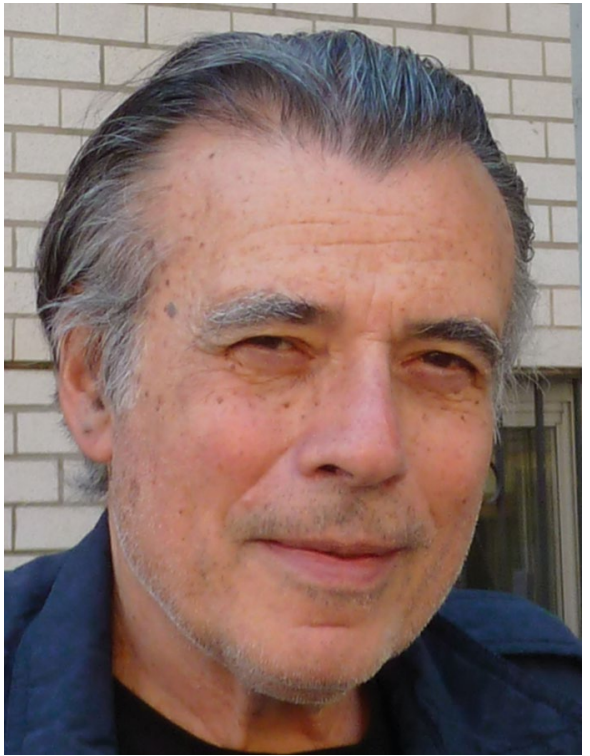

Credit: Lesley Downer

whose interests spanned the worlds of art and science. Among the highlights was an installation in which the artist Robert Rauschenberg used state-of-the-art electronics to subvert a game of tennis; and the cuttingedge musician John Cage's generation of 'new' sounds using complex electronics.

9 Evenings inspired the Londonbased curator Jasia Reichardt to develop Cybernetic Serendipity, which showcased the relationship between creativity and technology. Radio-controlled robots roamed the halls, stopping to kiss the curious and improvise on tunes that passers-by whistled into a microphone. Another popular exhibit was Colloquy of Mobiles, by the cybernetics researcher and psychologist Gordon Pask. It demonstrated how forms made up of electronic components could communicate and learn about one another by exchanging signals without any human intervention.

For the most part, this work was done through science influencing art, which still dominates the art and science scene. Today, such works usually appear only in specialist galleries. Owners of more standard galleries tend to shy away, largely because of their lack of understanding of science and technology, in addition to saleability issues.

But the arrow can turn the other way too: art influencing science. Cubism was important for the Danish physicist Niels Bohr in discovering the complementarity principle of quantum physics, and Harry Kroto's experience as a graphic designer led to his discovering the structure of $\mathrm{C}_{60}$.

Another way forward is the very recent feedback loop between art, science, technology and artificial intelligence (AI). The hybrid artists that populate this scene are artist, scientist and technologist rolled into one.

Today's most up-to-date art is created with AI. Its surreal images could not have been imagined beforehand, because they represent how machines see the world in which they live. This is the new avant-garde.

Prime examples are images first created by the computer vision programme DeepDream and then by an exciting development in AI: generative adversarial networks and their spinoffs Pix2Pix and CycleGAN, as well as an algorithm that creates new styles of art - a creative adversarial network. Artworks created by these machines are beginning to be noticed by the art world. They have been auctioned at Christie's, where one sold for an eyepopping US $\$ 432,500$, and at Sotheby's, as well as being displayed at Miami Art Week.

All this raises questions that go right to the heart of human and machine creativity. Is this art? What criteria can be used to assess it? Can we use the same criteria that we use for evaluating art produced by humans? Can machines be considered artists in their right? What is aesthetics in this brave new world? Might AI art be the new art form?

These are exciting times to be a scientist, as science broadens to include art, which, in turn, can lead to a deeper understanding of invisible worlds. It is unarguable that momentous scientific advances have been made by those whose curiosity goes beyond science as it is normally thought of into philosophy, music and art.

Arthur I. Miller

University College London, London, UK.

e-mail:a.miller@ucl.ac.uk

Arthur I. Miller is the author of Einstein, Picasso, and Colliding Worlds. His most recent book, The Artist in the Machine: The World of AI-powered Creativity, will be published in September 2019 by MIT Press.

Published online: 7 May 2019

https://doi.org/10.1038/s41565-019-0448-4 